\title{
Germline predisposition to genitourinary rhabdomyosarcoma
}

\author{
Kami Wolfe Schneider ${ }^{1}$, Nicholas G. Cost ${ }^{2}$, Kris Ann P. Schultz ${ }^{3}$, Shayna Svihovec ${ }^{4}$, Alexandra Suttman ${ }^{1}$ \\ ${ }^{1}$ Department of Pediatrics, Division of Hematology, Oncology and Bone Marrow Transplantation, ${ }^{2}$ Department of Surgery, Division of Urology, \\ University of Colorado, Anschutz Medical Campus, Children's Hospital Colorado, Aurora, CO, USA; ${ }^{3}$ International Pleuropulmonary Blastoma \\ (PPB)/DICER1 Registry, Cancer and Blood Disorders Program, Children's Minnesota, Minneapolis, MN, USA; ${ }^{4}$ Department of Pediatrics, Division \\ of Genetics, University of Colorado, Anschutz Medical Campus, Children's Hospital Colorado, Aurora, CO, USA \\ Contributions: (I) Conception and design: KW Schneider, A Suttman; (II) Administrative support: All authors; (III) Provision of study materials: KW \\ Schneider, A Suttman, S Svihovec, KA Schultz; (IV) Collection and assembly of data: KW Schneider, A Suttman, S Svihovec, KA Schultz; (V) Data \\ analysis and interpretation: None; (VI) Manuscript writing: All authors; (VII) Final approval of manuscript: All authors. \\ Correspondence to: Kami Wolfe Schneider, MS, CGC. Children's Hospital Colorado, 13123 E. $16^{\text {th }}$ Ave, B115, Aurora, CO 80045, USA. \\ Email: kami.wolfe@gmail.com.
}

\begin{abstract}
Multiple genetic conditions predispose to the development of rhabdomyosarcoma. Much of the literature on rhabdomyosarcoma in genetic syndromes does not sub-divide the location or the pathology of the sarcomas. Therefore, there are limited data on genitourinary specific associations with certain genetic syndromes. We summarize, here, the primary differential considerations for rhabdomyosarcoma of the genitourinary system. Primary considerations include DICER1 pathogenic variation, Li-Fraumeni syndrome, constitutional mismatch repair deficiency, mosaic variegated aneuploidy, neurofibromatosis type 1, Noonan syndrome, other RASopathies, Costello syndrome, and Beckwith-Wiedemann syndrome. Some conditions may present with specific pathological, clinical and/or family history features, but for others, the genitourinary tumor may be the only presenting sign at the time of diagnosis. Genetic evaluation with counseling and/or testing may help identify an underlying tumor predisposition. This manuscript serves as an introduction to germline considerations for children with genitourinary rhabdomyosarcoma.
\end{abstract}

Keywords: Genetics; genetic counseling; germline; cancer predisposition; rhabdomyosarcoma; genitourinary; syndrome

Submitted Jan 06, 2020. Accepted for publication Jun 18, 2020.

doi: $10.21037 / \mathrm{tau}-20-76$

View this article at: http://dx.doi.org/10.21037/tau-20-76

\section{Introduction}

Rhabdomyosarcomas are malignant soft tissue tumors that arise from striated undifferentiated muscle cells. Multiple genetic conditions may predispose to the development of rhabdomyosarcoma (1). Much of the literature on RMS in genetic syndromes does not sub-divide the location or the pathology of the sarcomas. Therefore, data are limited on genitourinary $(\mathrm{GU})$ specific associations with certain genetic syndromes.

Potential sites of rhabdomyosarcoma (RMS) in the GU tract include para-testicular, bladder, prostate, urachal, vaginal, cervical, uterine, ovarian, or retroperitoneal. It is important to note the location when considering possible underlying genetic predisposition as some sites may be more typical for certain syndromes. Histologically, different subtypes of rhabdomyosarcoma may suggest certain genetic predispositions. For example, the primary histologic classifications of RMS are embryonal (including the botryoid and spindle cell variants) or alveolar (2-4); having anaplasia or botryoid type increases the likelihood of germline genetic predisposition $(5,6)$. The spindle cell variants are most common in the paratesticular region regardless of genetic predisposition.

As somatic molecular analyses are increasingly utililized, germline variants may also be detected somatically during pathological evaluation. Cytogenetically, within the alveolar subtype clinical evaluation of PAX3-FOXO1 or PAX7- 
FOXO1 chromosomal translocations and within the embryonal subtype, evaluation for allele loss at the $11 \mathrm{p} 15.5$ locus can aid in identifying associations with genetic syndromes (4). Additionally, other tumor types may have rhabdomyosarcomatous differentiation which may also increase the likelihood of a germline genetic predisposition.

In this article, we summarize possible genetic considerations for children with rhabdomyosarcoma of the genitourinary system. These include DICER 1 pathogenic variation, Li-Fraumeni syndrome, constitutional mismatch repair deficiency, mosaic variegated aneuploidy, neurofibromatosis type 1 , Noonan syndrome, other RASopathies, Costello syndrome, and BeckwithWiedemann syndrome. Some conditions may present with specific pathological, clinical and/or family history features, but for others, the genitourinary tumor may be the only presenting sign at the time of diagnosis. Genetic evaluation with counseling and/or testing may help identify an underlying condition.

\section{DICER1 pathogenic variation}

DICER1 is a gene that encodes Dicer, an endonuclease critical in microRNA processing (7). In 2009, this germline pathogenic variation was first described in association with pleuropulmonary blastoma (PPB), a rare thoracic sarcoma, seen most commonly in infants and children under age $7(8,9)$. Pleuropulmonary blastomas often have a significant rhabdomyosarcomatous component and may be misdiagnosed as thoracic embryonal RMS on limited biopsy specimens (10). Since the first description of DICER1 in association with PPB, the spectrum of DICER1related tumors has continued to expand and is now known to include a variety of benign and malignant neoplasms including ovarian and uterine tumors, renal tumors, brain tumors, nasal tumors, both thyroid nodules and thyroid cancer and macrocephaly (11-16).

Although pathogenic germline DICER1 variants are seen in between one in 2,529 and one in 10,600 individuals, most individuals with DICER1 germline variants do not develop sarcoma (17). Despite the good health of most individuals with DICER1 variants, the rarity of sarcoma in general leads to a marked elevation in relative risk for those individuals harboring pathogenic variants (18). In addition to tumors arising in individuals with germline DICER 1 variants, DICER1-related tumors may arise in individuals without apparent genetic risk through development of two somatically acquired mutations in DICER1. Nearly all DICER1-related tumors, however, whether arising in the setting of germline predisposition, mosaicism or biallelic somatic mutations, have a characteristic pattern: loss of function mutation (often germline) plus a "hotspot" mutation (generally somatically acquired) (19). These "hotspot" mutations are typically missense mutations confined to one of 5 codons within the RNase IIIb domain and can be used to distinguish recurrent from metachronous ovarian tumors. An important exception to this is when multiple tumors arise in an individual with a predisposing mutation in the RNase IIIb domain (20).

Within the GU system, ovarian tumors associated with DICER1 pathogenic variation include Sertoli-Leydig cell tumors, gynandroblastoma and ovarian sarcoma. DICER1related ovarian sarcomas include embryonal RMS as well as undifferentiated ovarian sarcoma $(21,22)$. A single case of ovarian fibrosarcoma bearing DICER1 variants has been reported (23). It should also be noted that Sertoli-Leydig cell tumors frequently contain heterologous elements, often sarcomatous which portend a poorer prognosis. Embryonal RMS of the uterine cervix (cERMS, predominantly botryoid type) and less commonly of the vagina and uterine corpus has also been observed $(6,24,25)$.

In the kidney, cystic nephroma is common in individuals with underlying germline pathogenic variants in DICER1, seen in up to $10 \%$ of PPB kindreds $(26,27)$. Rarely, transformation of cystic nephroma to anaplastic sarcoma of the kidney has been observed (28). A subset of Wilms tumors are also DICER1-related. Cystic or partially cystic renal tumors or renal tumors in association with a personal or family history of lung cyst(s), macrocephaly or thyroid nodules are particularly suggestive of DICER1 variation.

When a germline pathogenic DICER1 variant is identified, testing and surveillance recommendations are available for individuals and family members $(29,30)$. In early childhood, these recommendations include chest $\mathrm{X}$-rays, chest CT scans, and abdominal ultrasounds. As children age, additional recommendations include thyroid ultrasounds for males and females and pelvic ultrasounds for females. Annual ophthalmologic examination is recommended from age 3 until at least age 10. Throughout life, education regarding potential symptoms of concern and regular physical examinations remain important for individuals with pathogenic variants in DICER1 (30).

\section{Li-Fraumeni syndrome (LFS)}

LFS is an autosomal dominant hereditary condition 
caused by pathogenic mutations in the gene TP53. It is characterized by markedly increased risk for sarcoma, brain tumors, pre-menopausal breast cancer, and adrenocortical carcinoma, though a large variety of tumors have been reported in individuals with LFS (31). Current risk estimates quantify the cancer risk for childhood malignancy at approximately $40 \%$ (32), with cancer risk approaching $100 \%$ by age 70 (33). While these estimates are likely to be inflated by ascertainment bias, it is not uncommon to observe multiple cancer diagnoses over the course of an individual's lifetime, with cancers occurring at much younger ages than expected for a sporadic cancer. LFS is most commonly inherited, but may be de novo up to $25 \%$ of the time, and also exhibits variable penetrance (31). As such, a striking family history is not always observed, and a negative family history does not rule out the possibility of LFS. Given the substantial lifetime cancer risk for LFS patients, intensive surveillance guidelines including routine whole-body MRI have been published to reduce morbidity and mortality for LFS patients $(31,34)$, although these protocols may impart greater psychological burden. In addition, individuals with LFS have a sensitivity to radiation, and due to an increased risk for developing new sarcomas in radiation therapy fields, early identification of LFS by genetic testing can impact treatment decisions by reducing the desire to utilize radiation as local control and increasing consideration of more aggressive surgical local control.

Approximately $25 \%$ of individuals with LFS will develop a sarcoma in their lifetime (35). Sarcomas are more likely to be seen in individuals with a missense mutation in the DNA binding domain of TP53 (35). The risk for developing a RMS is approximately $4 \%$ for individuals with LFS, though data is not robust (35). RMS occurs almost exclusively in individuals with LFS under the age of 20 years, and children diagnosed before age 3 are especially likely to have LFS $(35,36)$. Anaplastic nonalveolar RMSs in early childhood is bighly associated with LFS (5), and so individuals with RMS of embryonal anaplastic subtype meet National Comprehensive Cancer Network genetic testing criteria for germline TP53 testing regardless of age and family history (37). Anaplastic subtype is associated with worse outcomes in embryonal RMS; other subsets of LFS-associated sarcomas may also be associated with a poorer prognosis (38). No currently available literature that we could find describes patterns of GU RMS in LFS, though risk for any GU malignancy is previously reported at 7\% (39). Reported childhood malignancies include RMS of the lower pelvis in a 50-month-old and right paratesticular RMS in a 40-month-old (5). Reported adult malignancies include pelvic angiosarcoma, pelvic sarcoma, sarcomatoid carcinoma of bladder, pelvic mesenchymal leiomyosarcoma, leiomyosarcoma of spermatic cord, and leiomyosarcoma of the bladder (39). Further research on the incidence and nature of RMS of the GU tract in LFS is warranted, especially given the high cancer risk and aggressive nature of LFS-related tumors.

\section{Mosaic variegated aneuploidy syndrome type 1}

Mosaic variegated aneuploidy syndrome is a very rare condition with features of microcephaly, physical anomalies including neurological anomalies and ambiguous genitalia in males, growth deficiency, intellectual disability and increased cancer risk (40). It is caused by improper spindle formation and chromosome separation during mitosis, leading to differing germline cellular aneuploidies at a mosaic state. This recessive condition is caused by mutations in BUB1, TRIP13, and CEP57, though individuals with mutations in CEP57 are not thought to have increased cancer risk, and individuals with mutations in TRIP13 are thought to be at highest risk for Wilms tumor development (41). Those with biallelic mutations in BUB1 exhibit risk for Wilms tumor, leukemia, and RMS (41).

While data is limited, RMS in mosaic variegated aneuploidy is highly likely to occur in the GU tract, primarily in the vagina and bladder, and is more likely to be embryonal and exhibit botryoid features. Three females are reported to have been diagnosed with a vaginal RMS at the ages of 13 months (42), 8 months (43), and 5 months (40). Two males have been reported with a bladder RMS at the ages of 13 months (42) and 7 months (44) with extension into the prostate gland. While the mechanism for why mosaic variegated aneuploidy causes RMS, primarily appearing within the GU tract, is not currently understood, it is important for providers caring for these patients to have a high degree of suspicion for any unusual masses or protrusions within the pelvic region. While surveillance recommendations for rare cancer predisposition syndromes like mosaic variegated aneuploidy are not widely published, when cancer risks are elevated but specifics are unknown, increased awareness and low threshold for investigating new potential tumor-related symptoms is essential (45). Additionally, identifying mosaic variegated aneuploidy in a patient with a GU RMS may help patients understand their risks for other clinical features and consider reproductive options. 


\section{Beckwith-Wiedemann syndrome (BWS)}

BWS is an overgrowth condition characterized by macroglossia, macrosomia, and hemihypertrophy. Affected individuals can also present with polyhydramnios in utero, neonatal hypoglycemia, visceromegaly, omphalocele and ear pits. These features are included amongst the major and minor criteria which provide an algorithm for a clinical diagnosis of BWS. Because there is a high risk for embryonal tumors in childhood, established surveillance protocols include renal ultrasounds every three months in addition to hepatic surveillance for hepatoblastoma (46-48). The most common genitourinary tumor seen in children with BWS is Wilms tumor, however, RMS accounts for $5 \%$ of the tumors found in the BWS population (47). The location of these tumors is not readily described, however, a study published in 2009 discussed locations of 9 rhabdomyosarcomas (8 previously published) and found three were embryonal, five were alveolar, and one was of unknown type. It is noted that $22 \%(2 / 9)$ of these tumors were located in the GU system (urinary bladder), two others were noted to be in the abdomen or pelvis with the specific organs affected not described (49). The age of onset for the two bladder tumors was age 2 and age 3 (age of onset of all of the RMS tumors reported was between 22 days and 13 years) (49). Other rhabdomyosarcomas have been reported in those with BWS since the previously mentioned nine, however, the locations of these tumors were not well described. There are multiple mechanisms, both molecular and epigenetic, that can lead to BWS including paternal uniparental disomy, $11 \mathrm{p} 15$ paternal uniparental isodisomy, loss of methylation in imprinting center 2, or a gain of methylation in imprinting center 1 . It is reported that $0.5-0.7 \%$ of patients with loss of methylation in imprinting center 2 have an RMS and that, $3 \%$ of patients with paternal uniparental disomy develop a RMS $(46,47)$. As in other reports, the location of these tumors was not described; more data is needed to understand the risk for GU RMS in those with BWS. Cytogenetic features of the RMS tumors differ between those associated with BWS and those that are isolated. The common $P A X 7$ or $P A X 3$ translocations that are often found in isolated RMS tumors were not found in the RMS tumors of individuals with BWS (50).

\section{Neurofibromatosis, type 1 (NF1)}

NF1 is an autosomal dominant RASopathy characterized by café au lait macules, axillary and inguinal freckling, Lisch nodules, and neurofibromas. Optic and non-optic gliomas and peripheral nerve sheath tumors are commonly seen with this diagnosis. Management guidelines for individuals with NF1 focus on tumor surveillance as well as other complications (e.g., renal artery stenosis, optic gliomas impacting visual acuity, or pheochromocytoma leading to hypertension) (51-53). Executive functioning can also be impacted in those with NF1 and learning delays are common (54). Approximately $50 \%$ of the time, NF1 is inherited from an affected parent while the other $50 \%$ of the time it is brand new in an individual, or de novo (53).

While certain tumors are common in NF1, RMS is rare (5). The risk is reported to be about $0.5 \%$, or 1 in 200, for an individuals with NF1 to develop a RMS. All of the RMS tumors reported in individuals with NF1 have been embryonic in origin, and the literature indicates that a higher proportion of these are urogenital, particularly seen in the bladder/prostate (55-57). The study put forth by Crucis et al. noted that 11 out of $16(69 \%)$ of the RMS tumors found in the NF1 cohort were found in the $\mathrm{GU}$ regions. One other was found in the "pelvic region" making it unclear if it affected a GU organ. Another study found 5/6 (83\%) to be GU in origin, two in the paravesical space, two in the bladder, and one was paratesticular (58). A summary of other informative case studies, including the two noted above, found 27/39 $(69 \%)$ to be in the GU tract or abdomen (55). It is also documented that about $1 \%$ of individuals with RMS will have NF1 $(55,56)$. Of the defined GU tract RMS tumors in the two series noted above, 13/16 were diagnosed before age three and the oldest age of diagnosis was 5.4 years old (55). It is also noted that RMS in NF1 is less likely to be metastatic than idiopathic RMS (55). Overall, although the incidence of any RMS in NF1 is rare, the risk of developing RMS is thought to be 20 times greater than in the general population. Approximately $70 \%$ of RMS tumors associated with $\mathrm{NF} 1$ are located in the GU tract, compared to only $18 \%$ of idiopathic tumors $(55,57)$. It is important to consider that the diagnosis of NF1 is frequently established clinically and most of the patients in these case reviews were noted not to have had genetic testing. It is possible that these patients may have a condition that is not NF1 but similar in presentation (55).

\section{Noonan syndrome (NS)}

NS is another autosomal dominantly inherited RASopathy 
with variable presentation including developmental delays, learning problems, webbed neck, congenital heart defects, hypertrophic cardiomyopathy (HCM), and hematologic cancer (59). Pulmonary valve stenosis is the most common heart defect found in those with Noonan syndrome. The presence or absence of a congenital heart defect does not impact the risk for hypertrophic cardiomyopathy later in life and surveillance for this continues throughout the lifespan. There are a large number of genes that are thought to cause Noonan syndrome, and some confer differing risks for certain features like HCM, learning disabilities, and malignancy. There is a large spectrum of severity amongst those with Noonan syndrome and it is not uncommon for an individual to be diagnosed as an adult after the diagnosis of a child (59).

In addition to the risk for blood cancers, there are six reports of RMS in individuals with Noonan syndrome (60-65). Of these six RMS tumors, all were embryonal (two were botryoid subtype and one was spindle cell subtype) and half were in the urogenital tract (vagina, urachus, bladder). Of the remaining three tumors, one was found in the orbit, one was in an unspecified region of the abdomen, and the third was in the biliary tract $(60,65)$. Age of onset ranged between 1 year and 9 years old with the average age of onset being about 4 years old for all RMS tumors in NS, whereas the ages of onset for the three individuals with a GU tumor were 4,4 , and 5 years old $(60,65)$. Because there are over 10 different genes that cause Noonan syndrome, genotype phenotype correlations have been explored. Interestingly, $75 \%$ (3/4) of the cases of RMS documented in individuals with Noonan syndrome who were molecularly tested had a mutation in SOS1 $(59,60,65)$. The fourth patient appears to have been tested for mutations in only particular exons in PTPN11 and HRAS and was not tested for mutations in SOS1 so the genotype of this patient remains unknown. Of the three patients with GU RMS tumors in this cohort only two had germline testing and both of these individuals has NS due to a mutation in SOS1 (60). More data is needed in order to draw concrete conclusions about the relationship between urogenital RMS and Noonan syndrome, particularly mutations in SOS1.

\section{Costello syndrome}

Costello syndrome is another rare RASopathy characterized by a spectrum of variable symptoms including feeding difficulties, short stature, intellectual disability, coarse facial features, cardiac complications, and an increased risk for tumors. This condition is incredibly variable with some severe individuals having lethal complications while others have a much more attenuated phenotype. Costello syndrome is inherited in an autosomal dominant pattern, but it is almost always caused by a de novo mutation in HRAS $(66,67)$.

Lifetime risk for any tumor is $15-17 \%$ for individuals with Costello syndrome; the most common tumors found are bladder carcinoma, neuroblastoma, and RMS $(67,68)$. RMS appears to be the tumor seen most frequently in these individuals, with the incidence of any RMS being $8.7 \%$ and the majority of these being of embryonal type $(63,69)$. Of the 26 patients published with Costello syndrome and RMS, 20 of them had the location of the tumor documented and 50\% (10/20) were found to be in the GU region. There were four other cases reported that were noted to be in the abdomen or pelvis but the specific location within that region was not defined. Four of these GU rhabdomyosarcomas were found in the urachus. Age of onset appears to be younger than non-syndromic RMS with the mean age of diagnosis in patients with Costello syndrome being 2 years 8 months old. A potential genotype-phenotype correlation has been suggested as 58\% (7/12) of the children with Costello, $H R A S$ results available, and a RMS (undefined locations) had the p.G12S germline variant (69). Further research is needed to confirm these findings.

\section{Other RASopathies}

There is limited information regarding RMS in RASopathies other those mentioned above. Both cardiofaciocutaneous syndrome (CFCS) and Noonan syndrome with multiple lentigines (NSML) have had reports of individuals with RMS, however, the locations of the tumors were not defined. CFCS is well defined by its name as the primary features include cardiac abnormalities, distinct facial features, and cutaneous malformations. This diagnosis is often made via molecular testing of the four genes currently known to be associated with the disease (KRAS, BRAF, MAP2K1, MAP2K2) (70). There is also debate as to whether the patient reported with CFCS and embryonal RMS might have actually had Costello syndrome as genetic testing was not completed (63). NSML is a condition that has overlapping features with Noonan syndrome with the addition of multiple lentigines. A diagnosis of NSML is often established by either clinical findings or molecular analysis of the currently known causative genes (PTPN11, RAF1, BRAF, and MAP2K1) (71). It is important to note that somatic variants in the RAS 
pathway have been observed frequently in embryonal RMS tumors. Studies have indicated that $40 \%$ of sporadic RMS cases contain a pathogenic variant in NRAS, BRAF, KRAS or NF1 (55). More data is needed in order to better understand what having a germline variant in the RAS pathway means for RMS risk.

\section{Constitutional mismatch repair deficiency (CMMRD)}

CMMRD is caused by biallelic pathogenic variants in the mismatch repair (MMR) genes, or genes associated with Lynch syndrome, including MLH1, MLH2, EPCAM, MSH6, and PMS2. CMMRD, like Li-Fraumeni syndrome, is a very aggressive cancer predisposition syndrome increasing the risk for Lynch syndrome type cancers in childhood as well as leukemia, lymphoma, and sarcoma, among others. Individuals with CMMRD may also present with NF1-like features, including café-au-lait macules (72). The C4CMMRD consortium developed a scoring system for the diagnosis of CMMRD, and CMMRD should be suspected in any patient reaching a score of 3 or more, via the system (73). Parents of patients with CMMRD are assumed to be obligate carriers and have Lynch syndrome, but depending on the gene mutated, family history may not be striking due to reduced penetrance, particularly with PSM2 and MSH6. As CMMRD is one of the most aggressive cancer predisposition syndromes, expert based surveillance guidelines exist and are recommended to commence in infancy or as soon as the diagnosis is established (72).

Given the rarity of this syndrome, the risk for sarcoma or RMS is not currently known. Previous reports of sarcoma include: RMS of unreported location diagnosed at age 4 (73), RMS of the left nasolabial fold at 3 years of age (74), RMS-like features in 16-year-old with right pterygoid fossa tumor (74), and a paravertebral alveolar soft part sarcoma at 8 years of age (75). Data on the risk and patterns of RMS in the GU tract for individuals of CMMRD is not currently available, though current case reports do not indicate a strong predilection for RMS of the GU tract in this syndrome. If an individual with RMS does have CMMRD, however, it is especially important to recognize early so that considerations for treatment and surveillance can address the elevated risks for developing a secondary malignancy.

\section{Genetic counseling considerations}

While other features may be present in the personal or family history (see Table 1), for many children RMS may be the first presenting sign of cancer predisposition. Referral for genetic counseling is appropriate for any individual diagnosed with a GU RMS. Identification of features listed in Table 1 in addition to a tumor diagnosis, may highlight the need for genetic counseling referral and/or genetic testing. When the clinical features are non-specific, next generation sequencing panels can evaluate for several cancer predisposition genes in a single analysis, however broad-based testing increases the likelihood of identifying variants of uncertain significance and may have limited or no ability to detect certain pathogenic variants or specific conditions, such as Beckwith-Wiedemann syndrome, for which methylation abnormalities are the most common etiology (47). Additionally, since much of the literature on RMS and genetic syndromes is not subdivided by the pathologic subtype or location, there are significant ambiguities when it comes to GU tumors. Genetic counselors are trained to discuss genetic matters that are not straightforward and can assist with these communications with both providers and families. In general, we suggest that a referral for genetic counseling is warranted for any patient with an anaplastic RMS at any age, embryonal RMS at 3 years of age or younger, sarcoma of the ovary, cervix, or uterus, RMS with somatic molecular features suggestive of germline predisposition, or RMS with personal or family history of any of the features in Table 1 (Figure 1) $(1,76)$. For most of these genetic syndromes, early and proper identification allows for implementation of medical management and surveillance strategies that can improve outcomes with early detection and prevention of manifestations.

\section{Conclusions}

Determining the etiology and pathophysiology of GU rhabdomyosarcoma has clinical importance both for individuals with RMS and for their family members. A tumor may be suspected to be related to genetic predisposition based on site of origin, histologic or radiographic appearance (e.g., a partially cystic renal tumor might suggest DICER1 pathogenic variation) or clinical characteristics such as patient age, clinical history, family history, or findings on physical exam (e.g., macrocephaly) (14). If a tumor is suspected to be related to a germline genetic predisposition syndrome, tumor-based testing and genetic counseling with potential germline testing may lead to improved clinical care. Tumors generally are most curable 
Table 1 Genetic syndromes associated with genitourinary (GU) rhabdomyosarcoma (RMS)

\begin{tabular}{|c|c|c|c|}
\hline $\begin{array}{l}\text { Syndromes associated with } \\
\text { GU RMS }\end{array}$ & Typical sarcoma features & $\begin{array}{c}\text { Typical/Reported sarcoma } \\
\text { locations }\end{array}$ & $\begin{array}{l}\text { Other possible clinical features of } \\
\text { syndrome }\end{array}$ \\
\hline DICER1 & $\begin{array}{l}\text { Rhabdomyosarcomatous } \\
\text { and cartilaginous histologic } \\
\text { features; anaplasia may be } \\
\text { present }\end{array}$ & $\begin{array}{l}\text { Ovarian, uterine (especially } \\
\text { uterine cervix) and vaginal; } \\
\text { Outside the GU system, } \\
\text { pulmonary, renal, intracranial }\end{array}$ & $\begin{array}{l}\text { Lung or renal cysts, macrocephaly, } \\
\text { thyroid nodules/thyroid cancer, nasal or } \\
\text { eye tumors }\end{array}$ \\
\hline $\begin{array}{l}\text { Mosaic variegated } \\
\text { aneuploidy syndrome type } 1\end{array}$ & Botryoid features & Vagina and bladder & $\begin{array}{l}\text { Growth deficiency, microcephaly, } \\
\text { distinctive facial features, neurologic } \\
\text { anomalies, intellectual disability, } \\
\text { ambiguous genitalia in males }\end{array}$ \\
\hline Neurofibromatosis, type 1 & Embryonal & $\begin{array}{l}\text { Urinary bladder, prostate, } \\
\text { some reports of paratesticular } \\
\text { and paravesical tumors }\end{array}$ & $\begin{array}{l}\text { Café au lait macules, axillary and } \\
\text { inguinal freckling, Lisch nodules, and } \\
\text { neurofibromas }\end{array}$ \\
\hline Noonan & $\begin{array}{l}\text { Embryonal (two with botryoid } \\
\text { features and two with spindle } \\
\text { cell features) }\end{array}$ & $\begin{array}{l}\text { Vagina, urachus, urinary } \\
\text { bladder }\end{array}$ & $\begin{array}{l}\text { Congenital heart defects (most common } \\
\text { is pulmonary valve stenosis), webbed } \\
\text { neck, hypertrophic cardiomyopathy, } \\
\text { distinct facial features, short stature, } \\
\text { learning delays }\end{array}$ \\
\hline Costello & Embryonal & $\begin{array}{l}\text { Urachus, undefined pelvic } \\
\text { region }\end{array}$ & $\begin{array}{l}\text { Coarse facial features, intellectual } \\
\text { disability, short stature, cardiac } \\
\text { concerns, feeding difficulties }\end{array}$ \\
\hline
\end{tabular}

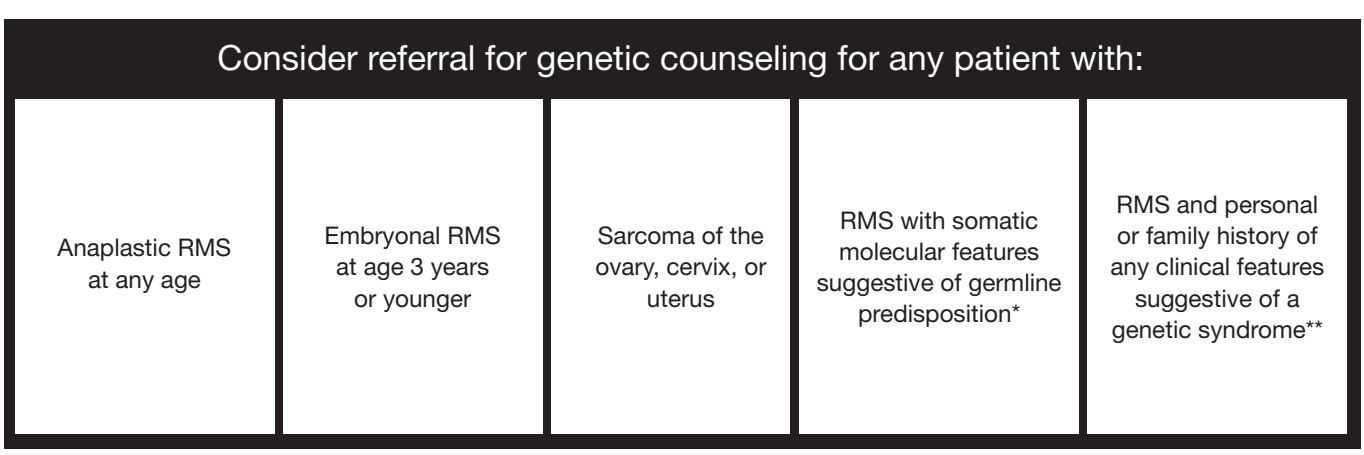

Figure 1 Indications for Genetic Counseling and/or Testing. RMS, rhabdomyosarcoma. *For example, a somatic pathogenic variant detected in a gene associated with germline predisposition. ${ }^{*}$ See Table 1. 
and require less intensive treatment when found in their earliest forms. Thus, identifying a genetic predisposition and detecting further tumors that develop early may improve disease-related prognosis and spare individuals (and potentially their family members) the toxicities of chemotherapy and radiation (29,34). Likewise, nephronsparing surgical options may be especially important considerations for individuals with germline predisposition and risk for bilateral disease or other renal disease. When a germline pathogenic variant in a cancer predisposition gene is identified, treatment decisions may be altered, and testing and surveillance recommendations may be considered for both the child and family members. Published guidelines for surveillance of children with hereditary cancer predisposition are available and may be used to reduce the risk of future complications (77). Additional research is needed to clarify the impact of hereditary predisposition on stage-specific outcomes and define optimal therapy. Since GU rhabdomyosarcomas associated with specific genetic syndromes are rare, international collaboration and research is encouraged.

\section{Acknowledgments}

Authors would like to thank the editors of Translational Andrology and Urology for inviting us to submit this manuscript, and all individuals, families, referring providers, genetic counselors and physicians who participate in and support collaborative rare tumor research.

Funding: None.

\section{Footnote}

Provenance and Peer Review: This article was commissioned by the Guest Editors (John Wiener, Jonathan Routh and Nicholas Cost) for the series "Pediatric Urologic Malignancies" published in Translational Andrology and Urology. The article was sent for external peer review organized by the Guest Editors and the editorial office.

Conflicts of Interest: All authors have completed the ICMJE uniform disclosure form (available at http://dx.doi. org/10.21037/tau-20-76). The series "Pediatric Urologic Malignancies" was commissioned by the editorial office without any funding or sponsorship. NGC served as the unpaid Guest Editor of the series. Dr. Schultz reports grants from Pine Tree Apple Classic Fund, Children's Minnesota and Rein in Sarcoma, during the conduct of the study. The authors have no other conflicts of interest to declare.

Ethical Statement: The authors are accountable for all aspects of the work in ensuring that questions related to the accuracy or integrity of any part of the work are appropriately investigated and resolved.

Open Access Statement: This is an Open Access article distributed in accordance with the Creative Commons Attribution-NonCommercial-NoDerivs 4.0 International License (CC BY-NC-ND 4.0), which permits the noncommercial replication and distribution of the article with the strict proviso that no changes or edits are made and the original work is properly cited (including links to both the formal publication through the relevant DOI and the license). See: https://creativecommons.org/licenses/by-nc-nd/4.0/.

\section{References}

1. Scollon, S, Anglin AK, Thomas M, et al. A Comprehensive Review of Pediatric Tumors and Associated Cancer Predisposition Syndromes. J Genet Couns 2017;26:387-434.

2. Newton WA Jr, Gehan EA, Webber BL, et al. Classification of rhabdomyosarcomas and related sarcomas. Pathologic aspects and proposal for a new classificationan Intergroup Rhabdomyosarcoma Study. Cancer 1995;76:1073-85.

3. Qualman SJ, Coffin CM, Newton WA, et al. Intergroup Rhabdomyosarcoma Study: update for pathologists. Pediatr Dev Pathol 1998;1:550-61.

4. O'Brien D, Jacob AG, Qualman SJ et al. Advances in pediatric rhabdomyosarcoma characterization and disease model development. Histol Histopathol 2012;27:13-22.

5. Hettmer S, Archer NM, Somers GR, et al. Anaplastic rhabdomyosarcoma in TP53 germline mutation carriers. Cancer 2014;120:1068-75.

6. Foulkes WD, Bahubeshi A, Hamel N, et al. Extending the phenotypes associated with DICER1 mutations. Hum Mutat 2011;32:1381-4.

7. Anglesio, MS Wang Y, Yang W, et al. Cancer-associated somatic DICER1 hotspot mutations cause defective miRNA processing and reverse-strand expression bias to predominantly mature $3 \mathrm{p}$ strands through loss of $5 \mathrm{p}$ strand cleavage. J Pathol 2013;229:400-9.

8. Messinger YH, Stewart DR, Priest JR, et al. Pleuropulmonary blastoma: a report on 350 central pathology-confirmed pleuropulmonary blastoma cases by 
the International Pleuropulmonary Blastoma Registry. Cancer 2015;121:276-85.

9. Hill DA, Ivanovich J, Priest JR, et al. DICER1 mutations in familial pleuropulmonary blastoma. Science 2009;325:965.

10. Dehner LP. Pleuropulmonary blastoma is THE pulmonary blastoma of childhood. Semin Diagn Pathol 1994;11:144-51.

11. de Kock L, Priest JR, Foulkes WD, et al. An update on the central nervous system manifestations of DICER1 syndrome. Acta Neuropathol 2020;139:689-701.

12. Heravi-Moussavi A, Anglesio MS, Cheng SW, et al. Recurrent somatic DICER1 mutations in nonepithelial ovarian cancers. N Engl J Med 2012;366:234-42.

13. Khan NE, Bauer AJ, Schultz KAP, et al. Quantification of Thyroid Cancer and Multinodular Goiter Risk in the DICER1 Syndrome: A Family-Based Cohort Study. J Clin Endocrinol Metab 2017;102:1614-22.

14. Khan NE, Bauer AJ, Doros L, et al. Macrocephaly associated with the DICER1 syndrome. Genet Med 2017;19:244-8.

15. Mason KA, Navaratnam A, Theodorakopoulou E, et al. Nasal Chondromesenchymal Hamartoma (NCMH): a systematic review of the literature with a new case report. J Otolaryngol Head Neck Surg 2015;44:28.

16. Rio Frio T, Bahubeshi A, Kanellopoulou C, et al. DICER1 mutations in familial multinodular goiter with and without ovarian Sertoli-Leydig cell tumors. JAMA 2011;305:68-77.

17. Kim J, Field A, Schultz KAP, et al. The prevalence of DICER1 pathogenic variation in population databases. Int J Cancer 2017;141:2030-6.

18. Stewart DR, Best AF, Williams GM, et al. Neoplasm Risk Among Individuals With a Pathogenic Germline Variant in DICER1. J Clin Oncol 2019;37:668-76.

19. Brenneman M, Field A, Yang J, et al. Temporal order of RNase IIIb and loss-of-function mutations during development determines phenotype in DICER1 syndrome: a unique variant of the two-hit tumor suppression model. F1000Res 2015;4:214.

20. Chen KS, Stuart SH, Stroup EK, et al. Distinct DICER1 Hotspot Mutations Identify Bilateral Tumors as separate events. JCO Precis Oncol 2018;2:1-9.

21. Schultz KA, Harris A, Messinger Y, et al. Ovarian tumors related to intronic mutations in DICER1: a report from the international ovarian and testicular stromal tumor registry. Fam Cancer 2016;15:105-10.

22. Warren M, Hiemenz MC, Schmidt R, et al. Expanding the spectrum of dicer1-associated sarcomas. Mod Pathol
2020;33:164-74.

23. Melendez-Zajgla J, Mercado-Celis GE, Gaytan-Cervantes J, et al. Genomics of a pediatric ovarian fibrosarcoma. Association with the DICER1 syndrome. Sci Rep 2018;8:3252.

24. Doros L, Yang J, Dehner L, et al. DICER1 mutations in embryonal rhabdomyosarcomas from children with and without familial PPB-tumor predisposition syndrome. Pediatr Blood Cancer 2012;59:558-60.

25. de Kock L, Wu MK, Foulkes WD. Ten years of DICER1 mutations: Provenance, distribution, and associated phenotypes. Hum Mutat 2019;40:1939-53.

26. Boman F, Hill DA, Williams GM, et al. Familial association of pleuropulmonary blastoma with cystic nephroma and other renal tumors: a report from the International Pleuropulmonary Blastoma Registry. J Pediatr 2006;149:850-4.

27. Doros LA, Rossi CT, Yang J, et al. DICER1 mutations in childhood cystic nephroma and its relationship to DICER1-renal sarcoma. Mod Pathol 2014;27:1267-80.

28. Wu MK, Vujanic GM, Fahiminiya S, et al., Anaplastic sarcomas of the kidney are characterized by DICER1 mutations. Mod Pathol 2018;31:169-78.

29. Schultz KA, Harris A, Williams GM, et al. Judicious DICER1 testing and surveillance imaging facilitates early diagnosis and cure of pleuropulmonary blastoma. Pediatr Blood Cancer 2014;61:1695-7.

30. Schultz KAP, Williams GM, Kamihara J, et al. DICER1 and Associated Conditions: Identification of At-risk Individuals and Recommended Surveillance Strategies. Clin Cancer Res 2018;24:2251-61.

31. Kratz CP, Achatz MI, Brugieres L, et al. Cancer screening recommendations for individuals with Li-Fraumeni syndrome. Clin Cancer Res 2017;23:e38-45.

32. Bougeard G, Renaux-Petel M, Flaman JM, et al. Revisiting Li-Fraumeni Syndrome from TP53 Mutation Carriers. J Clin Oncol 2015;33:2345-52.

33. Mai PL, Best AF, Peters JA, et al. Risks of first and subsequent cancers among TP53 mutation carriers in the National Cancer Institute Li-Fraumeni syndrome cohort. Cancer 2016;122:3673-81.

34. Villani A, Shore A, Wasserman JD, et al. Biochemical and imaging surveillance in germline TP53 mutation carriers with Li-Fraumeni syndrome: 11 year followup of a prospective observational study. Lancet Oncol 2016;17:1295-305.

35. Ognjanovic S, Olivier M, Bergemann TL, et al. Sarcomas in TP53 germline mutation carriers: a review of the IARC 
TP53 database. Cancer 2012;118:1387-96.

36. Diller L, Sexsmith E, Gottlieb A, et al. Germline p53 mutations are frequently detected in young children with rhabdomyosarcoma. J Clin Invest 1995;95:1606-11.

37. NCCN. Genetic/Familial High-Risk Assessment: Breast, Ovarian, and Pancreatic. NCCN Guidelines Version 1.2020 2019; CRIT-4.

38. Correa H. Hereditary cancer syndromes in children. J Pediatr Genet 2016;5:84-8.

39. Murray K. S, Spaliviero M, Tonorezos ES, et al. LiFraumeni Syndrome-related Malignancies Involving the Genitourinary Tract: Review of a Single-institution Experience. Urology 2018;119:55-61.

40. Plaja A, Vendrell T, Smeets DFCM, et al. Variegated aneuploidy related to premature centromere division (PCD) is expressed in vivo and is a cancer-prone disease. Am J Med Genet 2001;98:216-23.

41. García-Castillo H, Vásquez-Velásquez AI, Rivera H, et al. Clinical and genetic heterogeneity in patients with mosaic variegated aneuploidy: delineation of clinical subtypes. Am J Med Genet 2008;146A:1687-95.

42. Furukawa T, Azakami S, Kurosawa H, et al. Cystic partially differentiated nephroblastoma, embryonal rhabdomyosarcoma, and multiple congenital anomalies associated with variegated mosaic aneuploidy and premature centromere division: a case report. J Pediatr Hematol Oncol 2003;25:896-9.

43. Nishitani-Isa M, Hiraumi Y, Nishida $Y$, et al. Rhabdomyosarcoma with premature chromatid separationmosaic variegated aneuploidy syndrome: Reducedintensity chemotherapy. Pediatr Int 2019;61:613-6.

44. Kajii T, Ikeuchi T, Yang Z, et al. Cancer-prone syndrome of mosaic variegated aneuploidy and total premature chromatid separation: Report of five infants. Am J Med Genet 2001;104:57-64.

45. Villani A, Greer MLC, Kalish JM, et al. Recommendations for Cancer Surveillance in Individuals with RASopathies and Other Rare Genetic Conditions with Increased Cancer Risk. Clin Cancer Res 2017;23:e83-e90.

46. Mussa A, Molinatto C, Baldassarre G, et al. Cancer Risk in Beckwith-Wiedemann Syndrome: A Systematic Review and Meta-Analysis Outlining a Novel (Epi)Genotype Specific Histotype Targeted Screening Protocol. J Pediatr 2016;176:142-149.e1.

47. Brioude F, Kalish J, Mussa A, et al. Clinical and molecular diagnosis, screening and management of BeckwithWiedemann syndrome: An international consensus statement. Nat Rev Endocrinol 2018;14:229-49.
48. Weksberg R, Shuman C, Beckwith JB. BeckwithWiedemann syndrome. Eur J Hum Genet 2010;18:8.

49. Kuroiwa M, Sakamoto J, Shimada A, et al. Manifestation of alveolar rhabdomyosarcoma as primary cutaneous lesions in a neonate with Beckwith-Wiedemann syndrome. J Pediatr Surg 2009;44:e31-5.

50. Piersigilli F, Auriti C, Mondì V, et al. Decreased CDKN1C Expression in Congenital Alveolar Rhabdomyosarcoma Associated with Beckwith-Wiedemann Syndrome. Indian J Pediatr 2016;83:1476-8.

51. Evans DGR, Salvador H, Chang VY, et al. Cancer and Central Nervous System Tumor Surveillance in Pediatric Neurofibromatosis 1. Clin Cancer Res 2017;23:e46-e53.

52. Ferner RE, Huson SM, Thomas N, et al. Guidelines for the diagnosis and management of individuals with neurofibromatosis 1. J Med Genet 2007;44:81-8.

53. Dunning-Davies BM, Parker AP. Annual review of children with neurofibromatosis type 1 . Arch Dis Child Educ Pract Ed 2016;101:102-11.

54. Lehtonen A, Howie E, Trump D, et al. Behaviour in children with neurofibromatosis type 1: cognition, executive function, attention, emotion, and social competence. Dev Med Child Neurol 2013;55:111-25.

55. Crucis A, Richer W, Brugières L, et al. Rhabdomyosarcomas in children with neurofibromatosis type I: A national historical cohort. Pediatr Blood Cancer 2015;62:1733-8.

56. Matsui I, Tanimura M, Kobayashi N, et al. Neurofibromatosis type 1 and childhood cancer. Cancer 1993;72:2746-54

57. Sung L, Anderson J, Arndt C, et al. Neurofibromatosis in children with Rhabdomyosarcoma: A report from the intergroup Rhabdomyosarcoma study IV. J Pediatr 2004;144:666-8.

58. Ferrari A, Bisogno G. Soft-tissue sarcomas in children and adolescents with neurofibromatosis type 1 . Cancer 2007;109:1406-12.

59. Romano AA, Allanson JE, Dahlgren J, et al. Noonan syndrome: clinical features, diagnosis, and management guidelines. Pediatrics 2010;126:746-59.

60. Jongmans MC, Hoogerbrugge PM, Hilkens L, et al. Noonan syndrome, the SOS1 gene and embryonal rhabdomyosarcoma. Genes Chromosomes Cancer 2010;49:635-41.

61. Khan S, Mcdowell H, Upadhyaya M, et al. Vaginal rhabdomyosarcoma in a patient with Noonan syndrome. J Med Genet 1995;32:743-5.

62. Moschovi M, Vassiliki T, Anna P, et al. Rhabdomyosarcoma 
in a Patient With Noonan Syndrome Phenotype and Review of the Literature. J Pediatr Hematol Oncol 2007;29:341-4.

63. Kratz CP, Rapisuwon S, Reed H, et al. Cancer in Noonan, Costello, cardiofaciocutaneous and LEOPARD syndromes. Am J Med Genet C Semin Med Genet 2011;157C:83-9.

64. Hastings R, Newbury-Ecob R, Ng A, et al. A further patient with Noonan syndrome due to a SOS1 mutation and rhabdomyosarcoma. Genes Chromosom Cancer 2010;49:967-8.

65. Denayer E, Devriendt K, de Ravel T, et al. Tumor spectrum in children with Noonan syndrome and SOS1 or RAF1 mutations. Genes Chromosom Cancer 2010;49:242-52.

66. Hennekam RC. Costello syndrome: an overview. Am J Med Genet Part C Semin Med Genet 2003;117C:42-8.

67. Gripp KW, Cormier-Daire V, Cohen M. Tumor predisposition in Costello syndrome. Am J Med Genet C Semin Med Genet 2005;137C:72-7.

68. Gripp KW, Scott C, Nicholson L, et al. Five additional Costello syndrome patients with rhabdomyosarcoma: Proposal for a tumor screening protocol. Am J Med Genet 2002;108:80-7.

69. Sánchez-Montenegro C, Vilanova-Sánchez, BarrenaDelfa S, et al. Costello Syndrome and Umbilical Ligament Rhabdomyosarcoma in Two Pediatric Patients: Case Reports and Review of the Literature. Case Rep Genet 2017;2017:1587610.

70. Tidyman WE, Rauen KA. The RASopathies:

Cite this article as: Schneider KW, Cost NG, Schultz KAP, Svihovec S, Suttman A. Germline predisposition to genitourinary rhabdomyosarcoma. Transl Androl Urol 2020;9(5):2430-2440. doi:10.21037/tau-20-76 developmental syndromes of Ras/MAPK pathway dysregulation. Curr Opin Genet Dev 2009;19:230-6.

71. Sarkozy A, Digilio MC, Dallapiccola B. Leopard syndrome. Orphanet J Rare Dis 2008;3:13.

72. Tabori U, Hansford JR, Achatz MI, et al. Clinical management and tumor surveillance recommendations of inherited mismatch repair deficiency in childhood. Clin Cancer Res 2017;23:e32-7.

73. Wimmer K, Kratz CP, Vasen HF, et al. Diagnostic criteria for constitutional mismatch repair deficiency syndrome: suggestions of the European consortium 'care for CMMRD' (C4CMMRD). J Med Genet 2014;51:355-65.

74. Kratz CP, Holter S, Etzler J, et al. Rhabdomyosarcoma in patients with constitutional mismatch-repair-deficiency syndrome. J Med Genet 2009;46:418-20.

75. Modi MB, Patel PN, Modi VM, et al. First reported case of alveolar soft part sarcoma in constitutional mismatch repair deficiency syndrome tumor spectrum - diagnosed in one of the siblings with constitutional mismatch repair deficiency. South Asian J Cancer 2017;6:41-3.

76. Druker H, Zelley K, McGee RB, et al. Genetic counselor recommendations for cancer predisposition evaluation and surveillance in the pediatric oncology patient. Clin Cancer Res 2017;23:e91-7.

77. Brodeur GM, Nichols KE, Plon SE, et al. Pediatric Cancer Predisposition and Surveillance: An Overview, and a Tribute to Alfred G. Knudsen Jr. Clin Cancer Res 2017;23:e1-5. 